\title{
AUDIT LINGKUNGAN DAN PENGENDALIAN TEKNOLOGI INFORMASI PADA PT. XYZ
}

\author{
Matheus Supriyanto Rumetna \\ Fakultas Ilmu Komputer, Program Studi Sistem Informasi \\ Universitas Victory Sorong \\ Email: matheus.rumetna@gmail.com
}

\begin{abstract}
ABSTRAK
Perkembangan Teknologi Informasi (TI) saat ini sangat berdampak pada berbagai aspek kehidupan, tanpa kecuali pada proses bisnis yang dilakukan oleh perusahaan. PT. XYZ merupakan salah satu perusahaan yang mengandalkan TI dalam operasional kerja, maka perlu dilakukan proses audit yang dikerjakan oleh auditor. Tujuannya adalah untuk memastikan apakah semua pengendalian (Environmental Controls, Physical Controls, Logical Controls, IS Controls) sesuai dengan ketentuan atau prosedur yang ada, baik dalam hal keamanan gedung kantor sampai kepada aplikasi yang digunakan. Metode yang digunakan, antara lain interview, survey, review (kebijakan/prosedur), perform tests of key controls dan audit techniques (audit software \& test data). Hasil yang diperoleh berupa informasi (temuan dan rekomendasi) yang dapat membantu PT. XYZ dalam kelancaran operasional sehari-hari, sehingga nantinya sistem yang ada menjadi maksimal, lebih efektif dan efisien dalam pengoperasiannya.
\end{abstract}

Kata kunci: information system audit program; information system audit programme; risk assessment; pengukuran kerja.

\begin{abstract}
The development of Information Technology (IT) is currently very impact on various aspects of life, without exception on the business processes undertaken by the company. PT. XYZ is one of the companies that rely on IT in operational work, it is necessary to do an audit process undertaken by the auditor. The goal is to ascertain whether all controls (Control Controls, Physical Controls, Logical Controls, IS Controls) are in accordance with existing provisions or procedures, both in the case of office building security to the applications used. Methods used include interview, survey, review (policy/procedure), perform tests of key controls and audit techniques (audit software \& test data). The results obtained in the form of information (findings and recommendations) that can help PT. XYZ in the smooth operation of everyday, so that later the existing system to be maximal, more effective and efficient in its operation.
\end{abstract}

Keywords: information system audit program; information system audit programme; risk assessment work measurement.

\section{PENDAHULUAN}

Perkembangan Teknologi Informasi (TI) saat ini sangat berdampak pada berbagai aspek kehidupan, tanpa kecuali pada proses bisnis yang dilakukan oleh perusahaan. Perusahaan atau organisasi cenderung memanfaatkan teknologi untuk meningkatkan efisiensi yang bertujuan mendongkrak pendapatan dan memperbaiki kinerja (1)(2)(3)(4). Pemanfaatan teknologi sudah menjadi hal yang sangat penting dalam proses bisnis. Fenomena tersebut mempengaruhi perilaku dan kebutuhan semua pihak yang berhubungan dengan perusahaan baik secara langsung maupun tidak langsung, termasuk auditor baik auditor internal maupun auditor eksternal (5)(6).

PT. XYZ adalah perusahaan yang bergerak di bidang jasa penyedia informasi lowongan kerja. Perusahaan ini didirikan pada tanggal 27 Maret 2006. Terdapat beberapa departemen dalam perusahaan ini, diantaranya Departemen Finance, Departemen Marketing, Departemen Corpcare dan Departemen Sales. Setiap Departemen terintegrasi dengan mengandalkan sistem informasi serta jaringan internet untuk menunjang serta memudahkan dalam melaksanakan pekerjaan, sehingga operasional perusahaan menjadi lebih efektif dan efisien, namun karena terintegrasi maka perlu dilakukan proses audit yang dikerjakan oleh auditor.

Ruang lingkup digunakan untuk mengetahui serta membatasi area kerja auditor dalam melakukan audit. Ruang lingkup disini mencakup lingkungan sekitar bangunan kantor PT. XYZ, setiap ruang kantor PT. XYZ, koneksi jaringan dan keamanannya, serta aplikasi JBOS yang digunakan oleh PT. XYZ. 
Tujuan audit adalah untuk memastikan apakah semua pengendalian (Environmental Controls, Physical Controls, Logical Controls, IS Controls) sesuai dengan ketentuan atau prosedur yang ada, baik dalam hal keamanan gedung kantor sampai kepada aplikasi yang digunakan. Agar dapat membantu PT. XYZ dalam kelancaran operasional sehari-hari, sehingga nantinya sistem yang ada menjadi maksimal, lebih efektif dan efisien dalam pengoperasiannya (7)(8).

\section{METODOLOGI PENELITIAN}

Beberapa metode yang auditor gunakan, antara lain Interview (pihak terkait), Survey (bagian terkait), Review (kebijakan/prosedur), Perform tests of key controls dan Audit techniques (Audit Software \& Test Data). Berikut penjelasan dari tiap metode yang digunakan (9)(10) :

a. Interview

Merupakan salah satu metode yang digunakan oleh auditor untuk melakukan interview (wawancara) secara langsung dengan bagian sales dari PT. XYZ, serta mantan manager sales.

b. Survey

Merupakan salah satu metode yang digunakan oleh auditor untuk melakukan peninjauan secara langsung dengan bagian sales serta dengan cara melihat aplikasi JBOS yang digunakan oleh PT. XYZ.

c. Review

Merupakan salah satu metode yang digunakan oleh auditor untuk mengerahui kebijakan serta prosedur yang ada dengan cara membaca prosedur yang terdapat pada aplikasi JBOS serta dengan bertanya langsung mengenai prosedur yang ada kepada mantan manager sales.

d. Perform tests of key controls

Merupakan salah satu metode yang digunakan oleh auditor untuk melakukan pengujian performa untuk pengendalian keamanan dari segi Environmental Controls, Physical Controls, Logical Controls, IS Controls. Untuk hasil performanya dapat dilihat pada Tabel 3.

e. Audit techniques

Terdapat beberapa teknik audit yang dapat digunakan dalam melakukan audit, namun disini auditor menggunakan 2 teknik, yaitu Audit Software \& Test Data.

1) Audit Software digunakan untuk membantu dalam melakukan tugas khusus.

2) Test Data digunakan untuk pengujian data dengan menggunakan data dummy yang dibuat oleh auditor.

\section{HASIL DAN PEMBAHASAN}

\subsection{Identifying Computer System}

Identifikasi sistem komputer dilakukan oleh auditor dengan maksud agar auditor lebih mengetahui secara jelas jumlah komputer, spesifikasi komputer, database management system (DBMS) sampai application description dari tiap komputer (lihat Tabel 1) bahkan dapat melakukan penilaian resiko (lihat Tabel 2) .

Tabel 1. Inventory of computing system

\begin{tabular}{|c|c|c|c|c|c|c|c|}
\hline No & $\begin{array}{c}\text { Computer } \\
\text { Software } \\
\text { Application } \\
\end{array}$ & DBMS & $\begin{array}{c}\text { Hardware } \\
\text { Spesification }\end{array}$ & $\begin{array}{l}\text { Primary } \\
\text { Operatin } \\
\text { g System } \\
\end{array}$ & $\begin{array}{c}\text { Jumla } \\
\boldsymbol{h} \\
\text { (Unit) }\end{array}$ & $\begin{array}{c}\text { Departmen } \\
\text { t / Process } \\
\text { Owner }\end{array}$ & $\begin{array}{c}\text { Application } \\
\text { description }\end{array}$ \\
\hline \multicolumn{8}{|c|}{ FINANCE } \\
\hline 1. & JBOS & $\begin{array}{l}\text { MySQ } \\
\text { L }\end{array}$ & $\begin{array}{l}\text { Notebook: } \\
\text { Lenovo } \\
\text { Thinkpad } \\
\text { X220 } \\
\text { Processor : } \\
\text { Intel Core i5 } \\
2.7 \mathrm{GHz} \\
\text { RAM : 4GB } \\
\text { DDR3 } \\
\text { HDD : 320GB } \\
\text { Layar : 12.5" }\end{array}$ & $\begin{array}{c}\text { Windows } \\
8\end{array}$ & 1 & $\begin{array}{l}\text { Manager } \\
\text { Finance }\end{array}$ & $\begin{array}{l}\text { Digunakan untuk } \\
\text { : } \\
\text { - } \quad \text { Decision } \\
\text { Support } \\
\text { System. } \\
\text { - } \quad \text { Menggantika } \\
\text { n tugas staff } \\
\text { ketika staff } \\
\text { yang } \\
\text { bersangkutan } \\
\text { tidak hadir. }\end{array}$ \\
\hline
\end{tabular}




\begin{tabular}{|c|c|c|c|c|c|c|c|}
\hline No & $\begin{array}{c}\text { Computer } \\
\text { Software } \\
\text { Application }\end{array}$ & $D B M S$ & $\begin{array}{c}\text { Hardware } \\
\text { Spesification }\end{array}$ & $\begin{array}{l}\text { Primary } \\
\text { Operatin } \\
\text { g System }\end{array}$ & $\begin{array}{c}\text { Jumla } \\
\text { h } \\
\text { (Unit) }\end{array}$ & $\begin{array}{c}\text { Departmen } \\
\text { t/Process } \\
\text { Owner }\end{array}$ & $\begin{array}{l}\text { Application } \\
\text { description }\end{array}$ \\
\hline 2. & JBOS & $\begin{array}{l}\text { MySQ } \\
\text { L }\end{array}$ & $\begin{array}{l}\text { PC : Intel Core } \\
\text { i3-4160 } \\
\text { 3.0GHz } \\
\text { RAM 2GB } \\
\text { DDR3 } \\
\text { HDD 500GB } \\
\text { Monitor : HP } \\
\text { 15.6" }\end{array}$ & $\begin{array}{c}\text { Windows } \\
7\end{array}$ & 10 & $\begin{array}{c}\text { Staff } \\
\text { Finance }\end{array}$ & 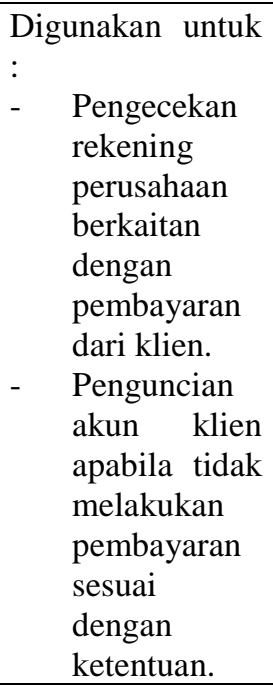 \\
\hline HR & & & & & & & \\
\hline 3. & JBOS & $\begin{array}{l}\text { MySQ } \\
\text { L }\end{array}$ & $\begin{array}{l}\text { Notebook: } \\
\text { Lenovo } \\
\text { Thinkpad } \\
\text { X220 } \\
\text { Processor : } \\
\text { Intel Core i5 } \\
2.7 \mathrm{GHz} \\
\text { RAM : 4GB } \\
\text { DDR3 } \\
\text { HDD : 320GB } \\
\text { Layar : 12.5" }\end{array}$ & $\begin{array}{c}\text { Windows } \\
8\end{array}$ & 1 & $\begin{array}{c}\mathrm{HR} \\
\text { (Manager) }\end{array}$ & $\begin{array}{l}\text { Digunakan untuk } \\
\text { : } \\
\text { - } \quad \text { Decision } \\
\text { Support } \\
\text { System. }\end{array}$ \\
\hline \multicolumn{8}{|c|}{ MARKETING } \\
\hline 4. & JBOS & $\begin{array}{l}\text { MySQ } \\
\text { L }\end{array}$ & $\begin{array}{l}\text { Notebook: } \\
\text { Lenovo } \\
\text { Thinkpad } \\
\text { X220 } \\
\text { Processor : } \\
\text { Intel Core i5 } \\
2.7 \mathrm{GHz} \\
\text { RAM : 4GB } \\
\text { DDR3 } \\
\text { HDD : 320GB } \\
\text { Layar : 12.5" }\end{array}$ & $\begin{array}{c}\text { Windows } \\
8\end{array}$ & 1 & $\begin{array}{l}\text { Marketing } \\
\text { (Manager) }\end{array}$ & $\begin{array}{l}\text { Digunakan untuk } \\
\text { : } \\
\text { - } \quad \text { Decision } \\
\text { Support } \\
\text { System. } \\
\text { - Menggantika } \\
\text { n tugas staff } \\
\text { ketika staff } \\
\text { yang } \\
\text { bersangkutan } \\
\text { tidak hadir. }\end{array}$ \\
\hline 5. & JBOS & $\begin{array}{l}\text { MySQ } \\
\text { L }\end{array}$ & $\begin{array}{l}\text { PC : Intel Core } \\
\text { i3-4160 } \\
3.0 \mathrm{GHz} \\
\text { RAM : 2GB } \\
\text { DDR3 } \\
\text { HDD : 500GB } \\
\text { Monitor : HP } \\
15.6 "\end{array}$ & $\begin{array}{c}\text { Windows } \\
7\end{array}$ & 11 & $\begin{array}{l}\text { Marketing } \\
\text { (Staff) }\end{array}$ & 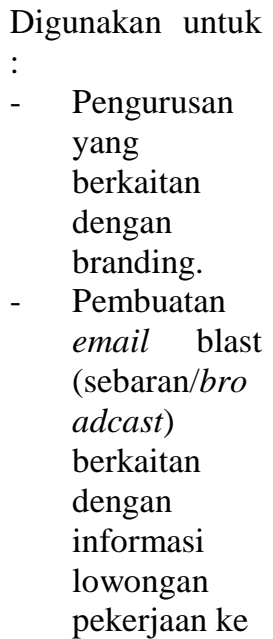 \\
\hline
\end{tabular}




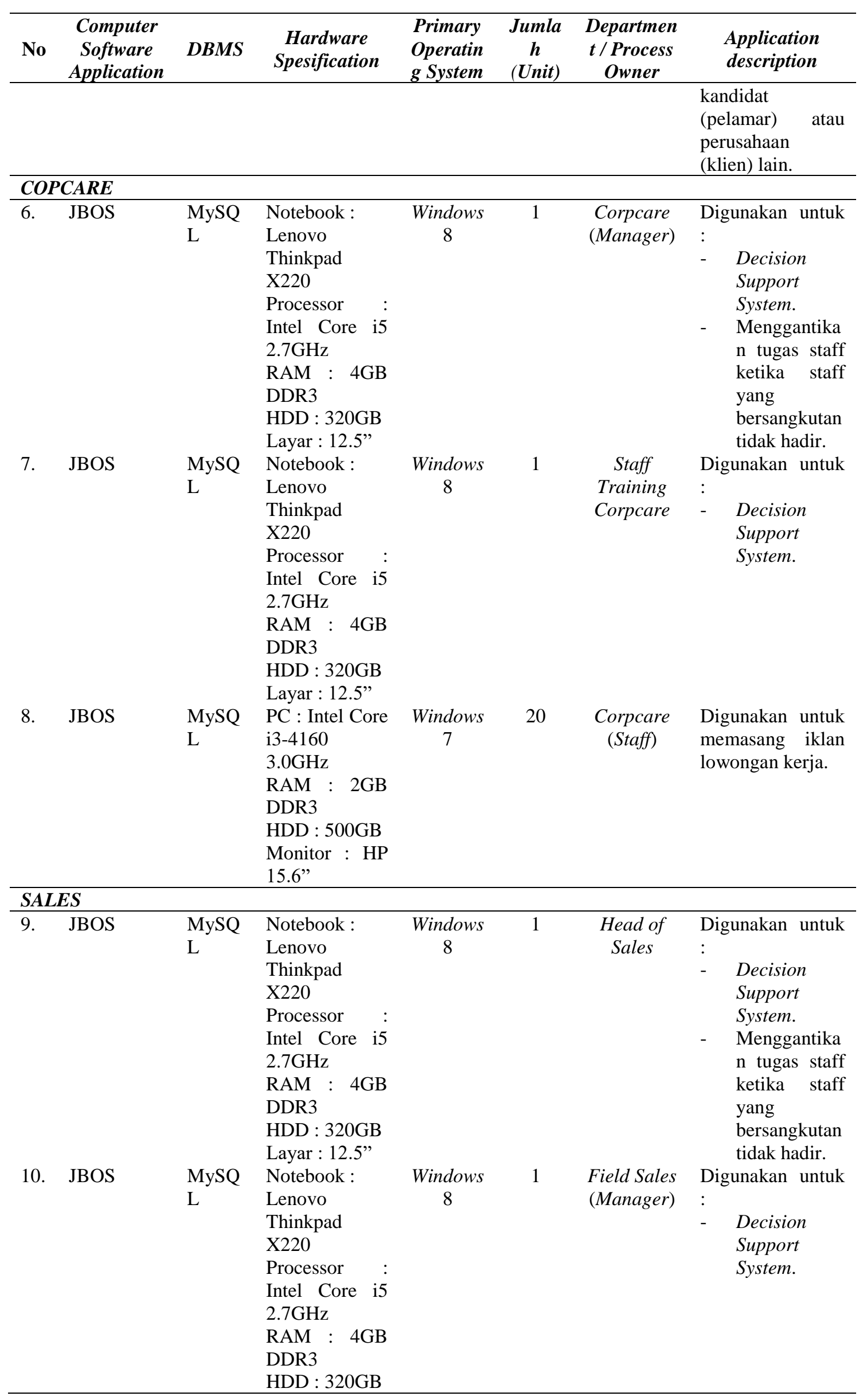




\begin{tabular}{|c|c|c|c|c|c|c|c|}
\hline No & $\begin{array}{c}\text { Computer } \\
\text { Software } \\
\text { Application }\end{array}$ & $D B M S$ & $\begin{array}{c}\text { Hardware } \\
\text { Spesification }\end{array}$ & $\begin{array}{l}\text { Primary } \\
\text { Operatin } \\
\text { g System }\end{array}$ & $\begin{array}{c}\text { Jumla } \\
\boldsymbol{h} \\
(\text { Unit })\end{array}$ & $\begin{array}{c}\text { Departmen } \\
\text { t / Process } \\
\text { Owner }\end{array}$ & $\begin{array}{c}\text { Application } \\
\text { description }\end{array}$ \\
\hline 11. & JBOS & $\begin{array}{l}\text { MySQ } \\
\text { L }\end{array}$ & $\begin{array}{l}\text { Layar: 12.5" } \\
\text { Notebook: } \\
\text { Lenovo } \\
\text { Thinkpad } \\
\text { X220 } \\
\text { Processor : } \\
\text { Intel Core i5 } \\
2.7 \mathrm{GHz} \\
\text { RAM : 4GB } \\
\text { DDR3 } \\
\text { HDD : } 320 \mathrm{~GB} \\
\text { Layar : 12.5" }\end{array}$ & $\begin{array}{l}\text { Windows } \\
8\end{array}$ & 1 & $\begin{array}{l}\text { Telesales } \\
\text { (Manager) }\end{array}$ & $\begin{array}{l}\text { Digunakan untuk } \\
\text { : } \\
\text { - } \text { Decision } \\
\text { Support } \\
\text { System. }\end{array}$ \\
\hline 12. & JBOS & $\begin{array}{l}\text { MySQ } \\
\text { L }\end{array}$ & $\begin{array}{l}\text { Notebook: } \\
\text { Lenovo } \\
\text { Thinkpad } \\
\text { X220 } \\
\text { Processor : } \\
\text { Intel Core i5 } \\
2.7 \mathrm{GHz} \\
\text { RAM : 4GB } \\
\text { DDR3 } \\
\text { HDD : 320GB } \\
\text { Layar : 12.5" }\end{array}$ & $\begin{array}{c}\text { Windows } \\
8\end{array}$ & 1 & $\begin{array}{l}\text { Assisten } \\
\text { Manager } \\
\text { Branch } \\
\text { (Sales) }\end{array}$ & $\begin{array}{l}\text { Digunakan untuk } \\
: \\
-\quad \text { Decision } \\
\text { Support } \\
\text { System. }\end{array}$ \\
\hline 13. & JBOS & $\begin{array}{l}\text { MySQ } \\
\text { L }\end{array}$ & $\begin{array}{l}\text { Notebook: } \\
\text { Lenovo } \\
\text { Thinkpad } \\
\text { X220 } \\
\text { Processor : } \\
\text { Intel Core i5 } \\
2.7 \mathrm{GHz} \\
\text { RAM : 4GB } \\
\text { DDR3 } \\
\text { HDD : 320GB } \\
\text { Layar : 12.5" }\end{array}$ & $\begin{array}{c}\text { Windows } \\
8\end{array}$ & 1 & $\begin{array}{l}\text { Assisten } \\
\text { Manager } \\
\text { Retention } \\
\text { Team } \\
\text { (Sales) }\end{array}$ & $\begin{array}{l}\text { Digunakan untuk } \\
\text { : } \\
\text { - } \quad \text { Decision } \\
\text { Support } \\
\quad \text { System. }\end{array}$ \\
\hline 14. & JBOS & $\begin{array}{l}\text { MySQ } \\
\text { L }\end{array}$ & $\begin{array}{l}\text { Notebook: } \\
\text { Lenovo } \\
\text { Thinkpad } \\
\text { X220 } \\
\text { Processor : } \\
\text { Intel Core i5 } \\
2.7 \mathrm{GHz} \\
\text { RAM : 4GB } \\
\text { DDR3 } \\
\text { HDD : 320GB } \\
\text { Layar : 12.5" }\end{array}$ & $\begin{array}{c}\text { Windows } \\
8\end{array}$ & 1 & $\begin{array}{l}\text { Manager } \\
\text { Telemarket } \\
\text { ing (Sales) }\end{array}$ & $\begin{array}{l}\text { Digunakan untuk } \\
\text { : } \\
\text { - } \quad \text { Decision } \\
\text { Support } \\
\text { System. }\end{array}$ \\
\hline 15. & JBOS & $\begin{array}{l}\text { MySQ } \\
\text { L }\end{array}$ & $\begin{array}{l}\text { PC : Intel Core } \\
\text { i3-4160 } \\
3.0 \mathrm{GHz} \\
\text { RAM : } 2 \mathrm{~GB} \\
\text { DDR3 } \\
\text { HDD : 500GB } \\
\text { Monitor : HP } \\
\text { 15.6" }\end{array}$ & $\begin{array}{c}\text { Windows } \\
7\end{array}$ & 65 & $\begin{array}{l}\text { Sales } \\
\text { (Staff) }\end{array}$ & $\begin{array}{l}\text { Digunakan untuk } \\
\text { : } \\
\text { - } \quad \text { Penjualan. } \\
\text { - } \quad \text { Maintanance } \\
\text { klien (after } \\
\text { sales } \\
\text { service). }\end{array}$ \\
\hline \multicolumn{8}{|c|}{ COUNTRY MANAGER } \\
\hline 16 & JBOS & $\begin{array}{l}\text { MySQ } \\
\text { L }\end{array}$ & $\begin{array}{l}\text { Notebook: } \\
\text { Lenovo } \\
\text { Thinkpad }\end{array}$ & $\begin{array}{c}\text { Windows } \\
8\end{array}$ & 1 & $\begin{array}{l}\text { Country } \\
\text { Manager }\end{array}$ & $\begin{array}{l}\text { Digunakan untuk } \\
\text { : } \\
-\quad \text { Decision }\end{array}$ \\
\hline
\end{tabular}




\begin{tabular}{|c|c|c|c|c|c|c|c|}
\hline No & $\begin{array}{c}\text { Computer } \\
\text { Software } \\
\text { Application }\end{array}$ & DBMS & $\begin{array}{c}\text { Hardware } \\
\text { Spesification }\end{array}$ & $\begin{array}{l}\text { Primary } \\
\text { Operatin } \\
\text { g System }\end{array}$ & $\begin{array}{c}\text { Jumla } \\
\boldsymbol{h} \\
\text { (Unit) }\end{array}$ & $\begin{array}{c}\text { Departmen } \\
\text { t/Process } \\
\text { Owner }\end{array}$ & $\begin{array}{c}\text { Application } \\
\text { description }\end{array}$ \\
\hline & & & $\begin{array}{l}\text { X220 } \\
\text { Processor : } \\
\text { Intel Core i5 } \\
2.7 \mathrm{GHz} \\
\text { RAM : 4GB } \\
\text { DDR3 } \\
\text { HDD : } 320 \mathrm{~GB} \\
\text { Layar : } 12.5 "\end{array}$ & & & & $\begin{array}{ll}\text { - } & \text { Support } \\
& \text { System. }\end{array}$ \\
\hline \multicolumn{8}{|c|}{ BUSINESS ANALYST } \\
\hline 17. & JBOS & $\begin{array}{l}\text { MySQ } \\
\text { L }\end{array}$ & $\begin{array}{l}\text { Notebook: } \\
\text { Lenovo } \\
\text { Thinkpad } \\
\text { X220 } \\
\text { Processor : } \\
\text { Intel Core i5 } \\
2.7 \mathrm{GHz} \\
\text { RAM : 4GB } \\
\text { DDR3 } \\
\text { HDD : 320GB } \\
\text { Layar : 12.5" }\end{array}$ & $\begin{array}{c}\text { Windows } \\
8\end{array}$ & 1 & $\begin{array}{c}\text { Business } \\
\text { Analyst }\end{array}$ & $\begin{array}{l}\text { Digunakan untuk } \\
\text { : } \\
\text { - } \quad \text { Decision } \\
\text { Support } \\
\quad \text { System. }\end{array}$ \\
\hline \multicolumn{8}{|c|}{ QUALITY ASSURANCE } \\
\hline 18. & JBOS & $\begin{array}{l}\text { MySQ } \\
\text { L }\end{array}$ & $\begin{array}{l}\text { Notebook: } \\
\text { Lenovo } \\
\text { Thinkpad } \\
\text { X220 } \\
\text { Processor : } \\
\text { Intel Core i5 } \\
2.7 \mathrm{GHz} \\
\text { RAM : 4GB } \\
\text { DDR3 } \\
\text { HDD : 320GB } \\
\text { Layar : 12.5" }\end{array}$ & $\begin{array}{c}\text { Windows } \\
8\end{array}$ & 1 & $\begin{array}{c}\text { Quality } \\
\text { Assurance }\end{array}$ & $\begin{array}{l}\text { Digunakan untuk } \\
\text { : } \\
\text { - } \quad \text { Decision } \\
\quad \text { Support } \\
\quad \text { System. }\end{array}$ \\
\hline \multicolumn{8}{|c|}{ OTHERS } \\
\hline 19. & & & $\begin{array}{l}\text { Printer Canon } \\
+ \text { Fotocopy }\end{array}$ & & 3 & & \\
\hline 20. & & & $\begin{array}{l}\text { Printer Canon } \\
+ \text { cetak foto }\end{array}$ & & 3 & & \\
\hline 21. & & & Printer Epson & & 1 & & \\
\hline
\end{tabular}

Setelah mengetahui secara jelas jumlah komputer spesifikasi komputer, DBMS dan application description dari tiap komputer, selanjutnya auditor melakukan risk assessment agar dapat mengetahui resiko dan dapat memberikan cara mengatasi resiko tersebut. Hal ini dapat di lihat pada Tabel 2.

Tabel 2. Risk assessment

\begin{tabular}{|c|c|c|c|c|c|}
\hline No & Risk description & $\begin{array}{c}\text { Probability } \\
\text { of } \\
\text { occurrence }\end{array}$ & $\begin{array}{c}\text { Impact of } \\
\text { occurrence }\end{array}$ & $\begin{array}{l}\text { Overall } \\
\text { risk } \\
\text { ranking }\end{array}$ & Control descriptions \\
\hline 1. & $\begin{array}{l}\text { Kerusakan, perubahan, } \\
\text { penyisipan, penipuan yang } \\
\text { dilakukan oleh pengguna } \\
\text { yang tidak sah baik } \\
\text { internal maupun external }\end{array}$ & 2 & 4 & 8 & $\begin{array}{l}\text { Menggunakan login akun } \\
\text { dengan id dan password. } \\
\text { Memasang keamanan pada } \\
\text { jaringan server untuk } \\
\text { menanggulangi masalah } \\
\text { hacker. }\end{array}$ \\
\hline 2. & $\begin{array}{l}\text { Hilang dan atau rusaknya } \\
\text { data karena bencana } \\
\text { (misalnya: } \\
\text { kebakaran, banjir, gempa }\end{array}$ & 3 & 4 & 12 & $\begin{array}{l}\text { Data telah tersimpan pada } \\
\text { server pusat dan server } \\
\text { cadangan. } \\
\text { Melakukan backup data }\end{array}$ \\
\hline
\end{tabular}




\begin{tabular}{|c|c|c|c|c|c|}
\hline No & Risk description & $\begin{array}{l}\text { Probability } \\
\text { of } \\
\text { occurrence }\end{array}$ & $\begin{array}{l}\text { Impact of } \\
\text { occurrence }\end{array}$ & $\begin{array}{l}\text { Overall } \\
\text { risk } \\
\text { ranking }\end{array}$ & Control descriptions \\
\hline & $\begin{array}{l}\text { bumi, gunung berapi, } \\
\text { terorisme, dll) }\end{array}$ & & & & $\begin{array}{l}\text { secara berkala. } \\
\text { Memasang anti virus yang } \\
\text { handal. }\end{array}$ \\
\hline 3. & $\begin{array}{l}\text { Data tidak dapat diakses } \\
\text { karena listrik padam, } \\
\text { koneksi internet terputus, } \\
\text { ataupun server down }\end{array}$ & 4 & 5 & 20 & $\begin{array}{l}\text { Menggunakan UPS pada } \\
\text { setiap PC dan juga } \\
\text { menyediakan generator } \\
\text { sebagai pembangkit tenaga } \\
\text { listrik cadangan. } \\
\text { Ketika server down maka } \\
\text { dilakukan backup data ke } \\
\text { server lain. }\end{array}$ \\
\hline 4. & $\begin{array}{l}\text { Pencurian perangkat keras } \\
\text { komputer, peripheral, } \\
\text { laptop, dll }\end{array}$ & 1 & 3 & 3 & $\begin{array}{l}\text { Menggunakan CCTV pada } \\
\text { setiap ruangan. } \\
\text { Menggunakan id untuk } \\
\text { masuk ke ruangan. }\end{array}$ \\
\hline 5. & Human error & 2 & 2 & 4 & $\begin{array}{l}\text { Memberikan pengarahan } \\
\text { atau prosedur untuk } \\
\text { penggunaan sistem kepada } \\
\text { setiap user yang terlibat } \\
\text { dalam sistem. }\end{array}$ \\
\hline 6. & $\begin{array}{l}\text { Kegagalan } \\
\text { mematuhi hukum dan } \\
\text { peraturan yang berkaitan } \\
\text { dengan privasi }\end{array}$ & 1 & 2 & 2 & $\begin{array}{l}\text { Menghimbau kepada user } \\
\text { agar mematuhi aturan yang } \\
\text { berlaku. }\end{array}$ \\
\hline 7. & $\begin{array}{l}\text { Pembajakan perangkat } \\
\text { lunak atau pelanggaran hak } \\
\text { cipta }\end{array}$ & 2 & 4 & 8 & $\begin{array}{l}\text { Memberikan hak cipta pada } \\
\text { sistem. }\end{array}$ \\
\hline 8. & $\begin{array}{l}\text { Biaya pemeliharaan yang } \\
\text { berlebihan dan biaya } \\
\text { upgrade }\end{array}$ & 1 & 2 & 2 & $\begin{array}{l}\text { Melakukan pemeliharaan } \\
\text { dan upgrade sesuai dengan } \\
\text { kebutuhan sistem yang } \\
\text { menjadi prioritas. }\end{array}$ \\
\hline
\end{tabular}

\footnotetext{
Bobot penilaian:

1: Tidak beresiko

2: Sedikit beresiko

3: cukup beresiko

4 : beresiko

5 : sangat beresiko
}

\subsection{Information System Audit Program}

Program audit sistem informasi dimaksudkan untuk memastikan apakah semua pengendalian (Environmental Controls, Physical Controls, Logical Controls, IS Controls) sesuai dengan ketentuan atau prosedur yang ada, baik dalam hal keamanan gedung kantor sampai kepada aplikasi yang digunakan. Secara rinci dapat dilihat pada Tabel 3.

Tabel 3. Information system audit programme

\begin{tabular}{|c|c|c|c|c|}
\hline Section & Procedures & Objectives & $\begin{array}{c}\text { Auditor/ } \\
\text { Date }\end{array}$ & $\begin{array}{l}\text { Result } \\
\text { of tests } \\
\end{array}$ \\
\hline \multirow[t]{2}{*}{$\mathbf{A}$} & Environmental Controls & & & \\
\hline & $\begin{array}{l}\text { 1. Memastikan apakah atasan } \\
\text { memberikan pengarahan atau } \\
\text { prosedur untuk penggunaan sistem } \\
\text { kepada setiap user yang terlibat } \\
\text { dalam sistem. Melakukan evaluasi, } \\
\text { apakah user telah mengikuti } \\
\text { arahan atau prosedur yang berlaku } \\
\text { dalam penggunaan sistem. }\end{array}$ & $\begin{array}{l}\text { Agar setiap } \text { user } \\
\text { mengerathui dan mengerti } \\
\text { prosedur yang ada dalam } \\
\text { sistem. }\end{array}$ & $\begin{array}{l}\text { Matheus } \\
\text { 26/10/1 } \\
6\end{array}$ & $\begin{array}{l}\text { Sudah } \\
\text { sesuai }\end{array}$ \\
\hline
\end{tabular}




\begin{tabular}{|c|c|c|c|c|}
\hline Section & Procedures & Objectives & $\begin{array}{c}\text { Auditor/ } \\
\text { Date }\end{array}$ & $\begin{array}{l}\text { Result } \\
\text { of tests }\end{array}$ \\
\hline & $\begin{array}{l}\text { 2. Meninjau apakah sistem telah } \\
\text { dipasang hak cipta. }\end{array}$ & $\begin{array}{l}\text { Agar sistem tidak dianggap } \\
\text { sebagi sistem yang ilegal. }\end{array}$ & $\begin{array}{l}\text { Matheus } \\
, 21 / 10 / 1 \\
6\end{array}$ & $\begin{array}{l}\text { Sudah } \\
\text { sesuai }\end{array}$ \\
\hline & $\begin{array}{l}\text { 3. Melakukan peninjauan setiap } \\
\text { dokumen pelaporan error dan } \\
\text { memastikan bahwa setiap } \\
\text { pelaporan mendapatkan } \\
\text { penanganan yang baik. }\end{array}$ & $\begin{array}{l}\text { Agar sistem berjalan } \\
\text { dengan baik dan dokumen } \\
\text { tersebut digunakan sebagai } \\
\text { acuan untuk memperbaiki } \\
\text { sistem. }\end{array}$ & $\begin{array}{l}\text { Matheus } \\
26 / 10 / 1 \\
6\end{array}$ & $\begin{array}{l}\text { Sudah } \\
\text { sesuai }\end{array}$ \\
\hline & $\begin{array}{l}\text { 4. Mendokumentasikan tindakan apa } \\
\text { yang telah diambil untuk } \\
\text { mengendalikan lingkungan akses } \\
\text { pada area-area seperti pusat data } \\
\text { dan setiap ruangan. }\end{array}$ & $\begin{array}{l}\text { Agar semua area-area } \\
\text { tercover dan terbatas hak } \\
\text { aksesnya, sehingga apabila } \\
\text { terjadi trouble mudah } \\
\text { untuk pengendaliannya. }\end{array}$ & $\begin{array}{l}\text { Matheus } \\
\text { 26/10/1 } \\
6\end{array}$ & $\begin{array}{l}\text { Sudah } \\
\text { sesuai }\end{array}$ \\
\hline & $\begin{array}{l}\text { 5. Memastikan bahwa divisi IT } \\
\text { adalah kelompok pendukung } \\
\text { dalam organisasi. Menentukan } \\
\text { apakah ada komite pengawas } \\
\text { efektif IT atau komite yang setara } \\
\text { dalam organisasi. }\end{array}$ & $\begin{array}{l}\text { Agar dapat mengawasi dan } \\
\text { melakukan maintenance } \\
\text { sistem serta menjadi } \\
\text { bagian pendukung dari } \\
\text { sebuah organisasi yang } \\
\text { sudah komputerisasi. }\end{array}$ & $\begin{array}{l}\text { Matheus } \\
26 / 10 / 1 \\
6\end{array}$ & $\begin{array}{l}\text { Sudah } \\
\text { sesuai }\end{array}$ \\
\hline B & \multicolumn{4}{|l|}{ Physical Controls } \\
\hline & $\begin{array}{l}\text { 1. Menentukan apakah pengendalian } \\
\text { lingkungan komputer berikut telah } \\
\text { terpasang: } \\
\text { a. Peralatan pemadaman api } \\
\text { (misalnya, sistem sprinkler dan } \\
\text { alat pemadam lainnya) } \\
\text { b. Uninterruptible power supply } \\
\text { (UPS) } \\
\text { c. Emergency Power System } \\
\text { (EPS) (misalnya, generator) } \\
\text { d. Pengontrol suhu dan } \\
\text { kelembaban pengendali } \\
\text { (memastikan cadangan AC } \\
\text { tersedia) }\end{array}$ & $\begin{array}{l}\text { Agar semua aset baik fisik } \\
\text { maupun non fisik } \\
\text { terlindungi dengan baik, } \\
\text { dan apabila terjadi masalah } \\
\text { sudah ada sistem untuk } \\
\text { pengendaliannya. }\end{array}$ & $\begin{array}{l}\text { Matheus } \\
\text { 26/10/1 } \\
6\end{array}$ & $\begin{array}{l}\text { Untuk } \\
\text { poin a, c } \\
\text { dan d } \\
\text { sudah } \\
\text { sesuai. } \\
\text { Tetapi } \\
\text { untuk } \\
\text { poin b } \\
\text { belum } \\
\text { sesuai }\end{array}$ \\
\hline & $\begin{array}{l}\text { 2. Memastikan bahwa seluruh akses } \\
\text { ke setiap ruang departemen } \\
\text { terbatas pada masing-masing } \\
\text { managemen dan staff agar semua } \\
\text { hak ases ke sistem berjalan dengan } \\
\text { semestinya. }\end{array}$ & $\begin{array}{l}\text { Agar hak akses yang telah } \\
\text { ditentukan berjalan dengan } \\
\text { baik serta apabila terjadi } \\
\text { trouble lebih cepat dalam } \\
\text { mencari letak } \\
\text { permasalahan tersebut. }\end{array}$ & $\begin{array}{l}\text { Matheus } \\
\text { 26/10/1 } \\
6\end{array}$ & $\begin{array}{l}\text { Sudah } \\
\text { sesuai }\end{array}$ \\
\hline & $\begin{array}{l}\text { 3. Meninjau apakah pemeliharaan } \\
\text { rutin dilakukan pada peralatan } \\
\text { sistem untuk memastikan kinerja } \\
\text { peralatan beroperasi sesuai } \\
\text { harapan. }\end{array}$ & $\begin{array}{l}\text { Agar sistem dan juga } \\
\text { seluruh peralatan yang ada } \\
\text { bekerja dengan baik, serta } \\
\text { terhindar dari kerusakan } \\
\text { besar yang mengganggu } \\
\text { kelancaran operasional } \\
\text { organisasi. }\end{array}$ & $\begin{array}{l}\text { Matheus } \\
26 / 10 / 1 \\
6\end{array}$ & $\begin{array}{l}\text { Sudah } \\
\text { sesuai }\end{array}$ \\
\hline & $\begin{array}{l}\text { 4. Meninjau apakah gedung dan } \\
\text { fasilitas sesungguhnya aman dari } \\
\text { bahaya bencana dan mendapatkan } \\
\text { dokumen tentang pengantisipasian } \\
\text { apabila terjadi bencana. }\end{array}$ & $\begin{array}{l}\text { Agar gedung serta fasilitas } \\
\text { yang ada terhindar dari } \\
\text { bencana serta semua user } \\
\text { yang ada dapat mengetahui } \\
\text { tindakan yang dilakukan } \\
\text { apabila terjadi bencana. }\end{array}$ & $\begin{array}{l}\text { Matheus } \\
26 / 10 / 1 \\
6\end{array}$ & $\begin{array}{l}\text { Sudah } \\
\text { sesuai }\end{array}$ \\
\hline & $\begin{array}{l}\text { 5. Mengidentifikasikan pengendalian } \\
\text { hardware yang dibangun ke dalam } \\
\text { peralatan komputer oleh produsen, } \\
\text { mengecek peralatan hardware } \\
\text { apakah sudah sesuai kebutuhan }\end{array}$ & $\begin{array}{l}\text { Agar peralatan komputer } \\
\text { yang digunakan benar- } \\
\text { benar sesuai kebutuhan dan } \\
\text { juga spesifikasi yang } \\
\text { dituntut dalam menunjang }\end{array}$ & $\begin{array}{l}\text { Matheus } \\
\text { 26/10/1 } \\
6\end{array}$ & $\begin{array}{l}\text { Sudah } \\
\text { sesuai }\end{array}$ \\
\hline
\end{tabular}




\begin{tabular}{|c|c|}
\hline Section & Procedures \\
\hline & sistem atau belum. \\
\hline $\mathbf{C}$ & Logical Controls \\
\hline & $\begin{array}{l}\text { 1. Mengidentifikasi seluruh aplikasi } \\
\text { yang menyediakan mekanisme } \\
\text { keamanan. Serta memastikan } \\
\text { apakah kemampuan berikut telah } \\
\text { dilaksanakan: } \\
\text { a. User id yang unik ditetapkan } \\
\text { kepada semua pengguna. } \\
\text { b. Terminal secara otomatis akan } \\
\text { log off setelah } 30 \text { menit tidak } \\
\text { aktif. } \\
\text { c. Pengguna diharuskan untuk } \\
\text { mengubah password } \\
\text { setidaknya setiap } 90 \text { hari. } \\
\text { d. Password lama tidak dapat } \\
\text { digunakan kembali. } \\
\text { e. Sandi yang benar akan } \\
\text { disembunyikan pada sistem. }\end{array}$ \\
\hline
\end{tabular}

2. Memastikan otorisasi yang tepat diperoleh sebelum memberikan akses pengguna ke sumber daya sistem. Mengevaluasi prosedur yang ditetapkan untuk menghapus user id atau password dari sistem ketika seorang karyawan pergi.

3. Mengecek apakah ada proses perubahan program aplikasi. Meninjau prosedur apabila terjadi perubahan untuk memastikan fungsi-fungsi penting berikut dilakukan:

a. Tidak ada perubahan harus dilakukan untuk program dan file hingga otorisasi diberikan secara tertulis.

b. Hanya programmer komputer yang dapat melakukan perubahan.

c. Mendokumentasikan permintaan perubahan program.

d. Persetujuan pengguna atas permintaan perubahan.

4. Memastikan bahwa semua user telah memperoleh pemahaman tentang proses pengembangan sistem dan perubahan program.

5. Memastikan bahwa jaringan yang digunakan telah terpasang sistem keamanan (ter-enkripsi) yang baik agar dapat melindungi data (dari pihak yang tidak bertanggung

c. Agar terhindar dari pembobolan password.

d. Agar terhindar dari pembobolan password karena sudah pernah terekam dalam sistem.

e. Agar terhindar dari user nakal yang ingin melihat sandi user lainnya.

Agar membatasi hak akses Matheus Sudah dan pemberian hak , sesuai aksespun dilakukan oleh 26/10/1 otoritas yang tepat. Semua karyawan yang sudah keluar tidak dapat mengakses sistem.

Tujuan poin :

6

a. Agar semua proses perubahan

Matheus Sudah terdokumentasi dan pihak otorisasi mengetahui.

b. Agar perubahan sistem tertangani dengan baik dan dilakukan oleh orang yang tepat.

c. Agar semua perubahan terdokumentasi dan juga lebih gampang bagi divisi IT untuk melakukan perubahan.

d. Agar semua perubahan yang terjadi diketahui oleh pengguna.

$\begin{array}{lrll}\begin{array}{l}\text { Agar setiap } \\ \text { mengetahui }\end{array} & \begin{array}{l}\text { user } \\ \text { setiap }\end{array} & \text { Matheus } & \begin{array}{l}\text { Sudah } \\ \text { sesuai }\end{array} \\ \begin{array}{l}\text { perubahan sistem dan } \\ \text { mudah }\end{array} & 26 / 10 / 1 & \\ \text { menggunakan sistem. dalam } & 6 & \\ \begin{array}{l}\text { Agar jaringan yang } \\ \text { digunakan tidak mudah }\end{array} & \text { Matheus } & \text { Sudah } \\ \text { diretas/dibobol, sehingga } & 21 / 10 / 1 & \text { sesuai } \\ \text { data menjadi aman. } & 6 & \\ \end{array}$




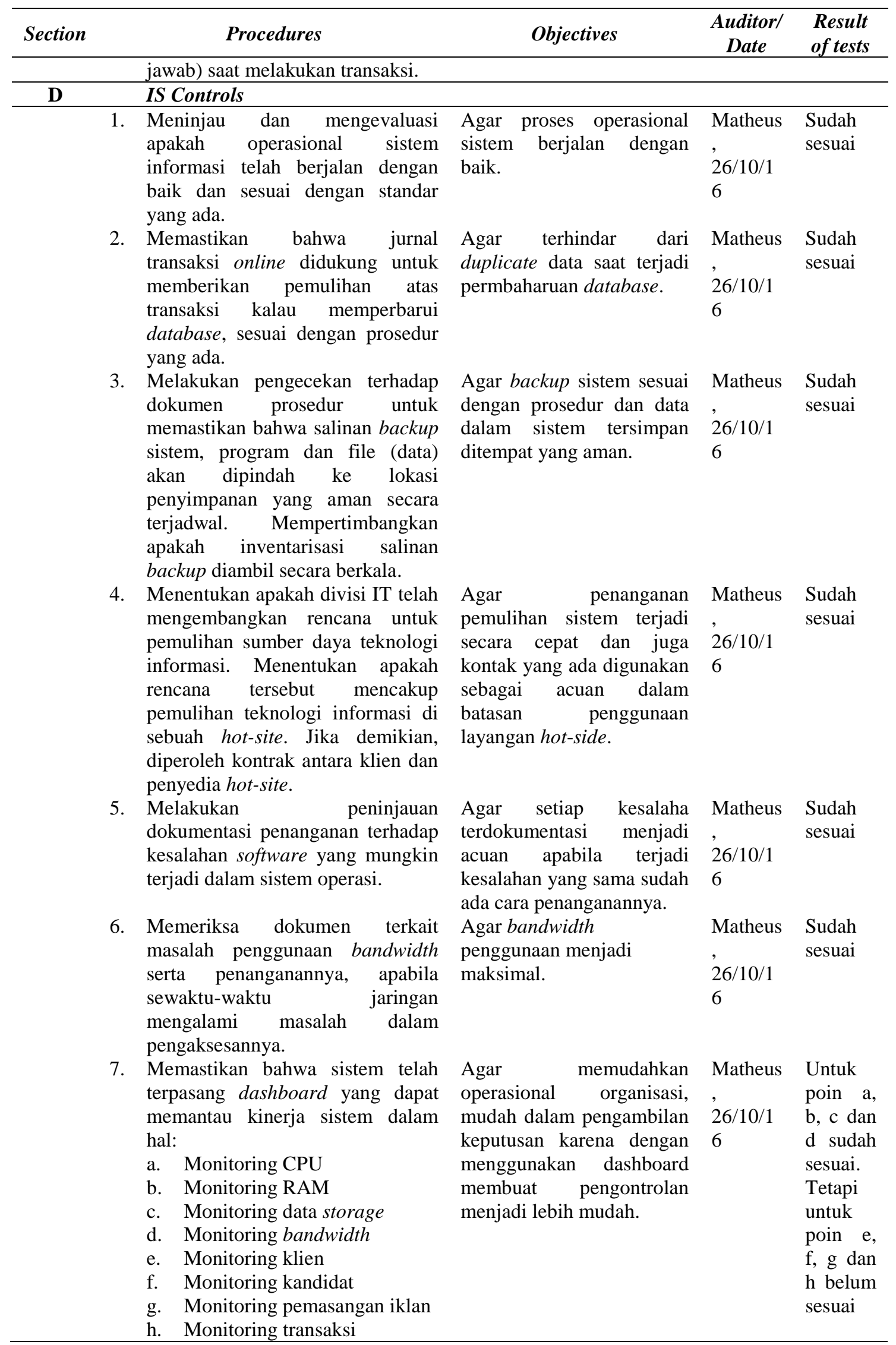




\subsection{Access Control Matrix}

Matriks akses kontrol digunakan oleh auditor sebagai acuan untuk mengetaui level user dan hak akses tiap user pada aplikasi JOBS. Lebih rinci matriks ini dapat dilihat pada Tabel 4.

Tabel 4. Access control matrix

\begin{tabular}{|c|c|c|c|c|c|c|c|c|}
\hline \multirow{3}{*}{$\begin{array}{l}\text { Menu Aplikasi } \\
\text { (Fungsi Menu) }\end{array}$} & \multicolumn{8}{|c|}{ Level User } \\
\hline & \multicolumn{2}{|c|}{ Sales } & \multicolumn{2}{|c|}{ Finance } & \multicolumn{2}{|c|}{ Marketing } & \multicolumn{2}{|c|}{ Corpcare } \\
\hline & $\begin{array}{l}\text { Staf } \\
f\end{array}$ & $\begin{array}{l}\text { Manag } \\
\text { er }\end{array}$ & $\begin{array}{l}\text { Staf } \\
f\end{array}$ & $\begin{array}{l}\text { Manag } \\
\text { er }\end{array}$ & $\begin{array}{l}\text { Staf } \\
f\end{array}$ & $\begin{array}{l}\text { Manag } \\
\text { er }\end{array}$ & $\begin{array}{l}\text { Staf } \\
f\end{array}$ & $\begin{array}{l}\text { Manag } \\
\text { er }\end{array}$ \\
\hline Menu Home & $\mathrm{R}$ & $\mathrm{R}$ & $\mathrm{R}$ & $\mathrm{R}$ & $\mathrm{R}$ & $\mathrm{R}$ & $\mathrm{R}$ & $\mathrm{R}$ \\
\hline $\begin{array}{lr}\text { Menu Order } & \text { (untuk } \\
\text { aktivasi } & \text { paket apa } \\
\text { diambil } & \text { oleh } \\
\text { client/company) } & \end{array}$ & $\begin{array}{l}\text { CR } \\
\text { UD }\end{array}$ & CRUD & & & & & & \\
\hline Menu Company 360 & $\mathrm{CR}$ & CRUD & $\mathrm{CR}$ & CRUD & & & CR & CRUD \\
\hline $\begin{array}{l}\text { (company detail nama } \\
\text { alamat no.telp) }\end{array}$ & UD & & UD & & & & UD & \\
\hline Menu History Pembelian & $\mathrm{R}$ & $\mathrm{R}$ & & & & & & \\
\hline Menu History & $\mathrm{R}$ & $\mathrm{R}$ & & & & & & \\
\hline Pembayaran & & & & & & & & \\
\hline $\begin{array}{l}\text { Menu Link ke Siva } \\
\text { Company }\end{array}$ & $\mathrm{R}$ & $\mathrm{R}$ & & & & & & \\
\hline 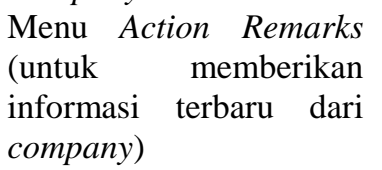 & $\begin{array}{l}\text { CR } \\
\text { UD }\end{array}$ & CRUD & & & & & & \\
\hline Menu Report & $\mathrm{R}$ & $\mathrm{R}$ & & & & & & \\
\hline Menu Transaction & & & $\begin{array}{c}\text { CR } \\
\mathrm{U}\end{array}$ & CRU & & & & \\
\hline Menu Payment & & & $\begin{array}{l}\text { CR } \\
\mathrm{U}\end{array}$ & CRU & & & & \\
\hline Menu Tax & & & $\begin{array}{c}\text { CR } \\
\text { U }\end{array}$ & CRU & & & & \\
\hline $\begin{array}{l}\text { Menu Mass Email (untuk } \\
\text { email blast) }\end{array}$ & & & & & $\begin{array}{l}\text { CR } \\
\text { UD }\end{array}$ & CRUD & & \\
\hline Menu Statistik & & & & & $\begin{array}{l}\text { CR } \\
\text { UD }\end{array}$ & CRUD & & \\
\hline $\begin{array}{l}\text { Menu Setting (untuk } \\
\text { setting waktu) }\end{array}$ & & & & & & & $\begin{array}{l}\text { CR } \\
\text { UD }\end{array}$ & CRUD \\
\hline $\begin{array}{l}\text { Catatan: } \\
C \quad: \text { create } \\
R \quad: \text { read } \\
U \quad: \text { update } \\
D \quad: \text { delete }\end{array}$ & & & & & & & & \\
\hline
\end{tabular}

\subsection{Computer Assisted Audit Techniques (CAATs)}

Audit Software digunakan oleh auditor untuk membantu dalam melakukan tugas khusus. Disini auditor memberikan contoh sebagai berikut :

Auditor menggunakan Microsoft Office Excel untuk mencari fraud "dugaan penggelapan uang penjualan package oleh sales dengan motif menghubungi klien (company) melalui email pribadi dan meminta untuk membayar tagihan ke rekening pribadi sales berdasarkan invoice."

Files dan Fields yang digunakan untuk pengujian dapat dilihat pada Tabel 5. 
Tabel 5. Files \& fields tested

\begin{tabular}{lll}
\hline \multicolumn{1}{c}{ Files } & \multicolumn{1}{c}{ Fields } & \multicolumn{1}{c}{ Fields Tested } \\
\hline Transaksi & 1) No. Invoice & 1) No. Invoice \\
& 2) Company Name & 2) Company Name \\
3) Package & 3) Package \\
& 4) Nama Sales & 4) Nama Sales \\
5) Activation Date & 5) Total \\
6) Amount & \\
7) Pajak (10\%) & \\
8) Total & 1) Company Name \\
1) Kode Company & 2) No. Telepon \\
2) Company Name & 3) Email \\
3) Alamat & \\
4) Kota & \\
5) No. Telepon & \\
6) Email & 1) Package \\
7) Website & 1) Nama Sales \\
1) Kode Package & 2) No.Telpon \\
2) Package & 3) Email \\
1) Kode Sales & \\
2) Nama Sales & 3) Alamat & \\
4) No.Telp & 5) Email &
\end{tabular}

Fungsi yang digunakan dalam pengujian adalah sebagai berikut :

a. SORT digunakan untuk mengurutkan Company Name secara Ascending.

b. FIND digunakan untuk mencari Company Name yang belum melakukan pembayaran tagihan berdasarkan invoice yang ada.

c. FIND juga digunakan untuk mencari nama Sales yang menangani transaksi terhadap klien yang belum melakukan pembayaran tagihan.

Berdasarkan uraian dugaan di atas, maka dilakukan pencarian fraud dengan cara berikut :

a. Pihak accounting mengecek invoice yang belum dibayarkan (open invoice) oleh pihak klien (company) melalui file transaksi. (IDJKINV/16100005)

b. Setelah menemukan open invoice tersebut, Accounting menghubungi Sales yang menangani transaksi pada saat itu. (Skil; 083949384)

c. Jika Sales tidak dapat dihubungi, maka Accounting akan mengecek siapa klien (Company) yang terdaftar dalam invoice tersebut melalui file transaksi. Selanjutnya, Accounting akan mencari No.Telp klien yang ditemukan melalui file Company. (PT. OPQ; 0848633)

d. Accounting melakukan konfirmasi pembayaran kepada PT. OPQ agar segera melunasi tagihan. Namun, pihak PT. OPQ mengatakan bahwa mereka telah melakukan pembayaran terhadap tagihan tersebut dengan transfer ke rekening Sales yang bersangkutan yaitu Skil.

e. Accounting meminta bukti transaksi kepada pihak PT. OPQ dan mereka mengirimkan bukti transaksi via bank dan juga via email.

f. Accounting menemukan nama Sales (Skil) pada bukti transfer uang ke rekening Skil yang seharusnya dikirim kepada pihak PT. XYZ.

g. Hasilnya, Accounting melaporkan kejadian ini ke Manager Sales dan atas tindakannya, maka Skil diberikan sanksi karena terbukti melakukan penggelapan uang penjualan package terhadap PT. OPQ.

\subsection{Working Paper of Test Data}

Test Data digunakan untuk pengujian data dengan menggunakan data dummy yang dibuat oleh auditor. Berikut contoh test data yang ditampilkan dalam Tabel 6. 
Tabel 6. Test data

\begin{tabular}{|c|c|c|c|c|c|c|}
\hline $\begin{array}{l}\text { Field } \\
\text { Name }\end{array}$ & $\begin{array}{c}\text { Dummy } \\
\text { Data }\end{array}$ & & $\begin{array}{c}\text { Tested } \\
\text { Control } \\
\text { (Option) }\end{array}$ & $\begin{array}{c}\text { Estimated } \\
\text { Result }\end{array}$ & $\begin{array}{c}\text { Occurred } \\
\text { Result }\end{array}$ & Conclusion/Finding \\
\hline \multirow[t]{2}{*}{$\begin{array}{l}\text { No. } \\
\text { Invoice }\end{array}$} & $\begin{array}{l}\text { IN2016101 } \\
9001\end{array}$ & $\checkmark$ & $\begin{array}{l}\text { Validity } \\
\text { check } \\
\text { Sequence } \\
\text { check }\end{array}$ & $\begin{array}{l}\text { Sistem } \\
\text { menerima }\end{array}$ & $\begin{array}{l}\text { Sistem } \\
\text { menerima }\end{array}$ & \\
\hline & $\begin{array}{l}201610190 \\
011221\end{array}$ & $\begin{array}{l}\checkmark \\
\checkmark\end{array}$ & $\begin{array}{l}\text { Size check } \\
\text { Check } \\
\text { digit }\end{array}$ & $\begin{array}{l}\text { Sistem } \\
\text { menolak } \\
\text { (maksimal } 13 \\
\text { digit) }\end{array}$ & $\begin{array}{l}\text { Sistem } \\
\text { menolak }\end{array}$ & $\begin{array}{lr}\text { No. Invoice yang } \\
\text { dimasukkan tidak } \\
\text { sesuai dengan jumlah } \\
\text { digit } \\
\text { dibatasi/ditentukan } \\
\text { dalam sistem }\end{array}$ \\
\hline \multirow{7}{*}{$\begin{array}{l}\text { Compa } \\
n y \\
\text { Name }\end{array}$} & $\begin{array}{l}\text { Dibiarkan } \\
\text { kosong }\end{array}$ & $\checkmark$ & $\begin{array}{l}\text { Completen } \\
\text { ess check }\end{array}$ & $\begin{array}{l}\text { Sistem } \\
\text { menolak }\end{array}$ & $\begin{array}{l}\text { Sistem } \\
\text { menolak }\end{array}$ & $\begin{array}{l}\text { Company Name tidak } \\
\text { boleh dibiarkan kosong }\end{array}$ \\
\hline & & $\checkmark$ & $\begin{array}{l}\text { Blank } \\
\text { check }\end{array}$ & $\begin{array}{l}\text { (company } \\
\text { name tidak } \\
\text { boleh kosong) }\end{array}$ & & $\begin{array}{l}\text { karena menyangkut } \\
\text { dengan pengolahan } \\
\text { data company }\end{array}$ \\
\hline & $\begin{array}{l}\text { PT. } \\
\text { Cendrawas } \\
\text { ih }\end{array}$ & $\checkmark$ & $\begin{array}{l}\text { Validity } \\
\text { check }\end{array}$ & $\begin{array}{l}\text { Sistem } \\
\text { menerima }\end{array}$ & $\begin{array}{l}\text { Sistem } \\
\text { menerima }\end{array}$ & \\
\hline & PT. X & $\checkmark$ & $\begin{array}{l}\text { Reasonabl } \\
\text { eness } \\
\text { check }\end{array}$ & $\begin{array}{l}\text { Sistem } \\
\text { menolak } \\
\text { (company }\end{array}$ & $\begin{array}{l}\text { Sistem } \\
\text { menolak }\end{array}$ & $\begin{array}{l}\text { Company Name tidak } \\
\text { sesuai dengan yang } \\
\text { terekam dalam sistem }\end{array}$ \\
\hline & & & & $\begin{array}{l}\text { name tidak } \\
\text { terdaftar) }\end{array}$ & & \\
\hline & PT. 56633 & $\checkmark$ & $\begin{array}{l}\text { Parity } \\
\text { check }\end{array}$ & $\begin{array}{l}\text { Sistem } \\
\text { menolak } \\
\text { (company }\end{array}$ & $\begin{array}{l}\text { Sistem } \\
\text { menolak }\end{array}$ & $\begin{array}{l}\text { Company Name tidak } \\
\text { sesuai dengan yang } \\
\text { terekam dalam sistem }\end{array}$ \\
\hline & & & & $\begin{array}{l}\text { name tidak } \\
\text { terdaftar) }\end{array}$ & & \\
\hline \multirow[t]{2}{*}{$\begin{array}{l}\text { Packag } \\
e\end{array}$} & $\begin{array}{l}1 \text { year } 30 \\
\text { jobs }\end{array}$ & $\checkmark$ & $\begin{array}{l}\text { Validity } \\
\text { check } \\
\text { Parity } \\
\text { check }\end{array}$ & $\begin{array}{l}\text { Sistem } \\
\text { menerima }\end{array}$ & $\begin{array}{l}\text { Sistem } \\
\text { menerima }\end{array}$ & \\
\hline & $\begin{array}{l}1 \text { month } 50 \\
\text { jobs }\end{array}$ & $\begin{array}{l}\checkmark \\
\checkmark\end{array}$ & $\begin{array}{l}\text { Reasonabl } \\
\text { eness } \\
\text { check } \\
\text { Existence } \\
\text { check }\end{array}$ & $\begin{array}{l}\text { Sistem } \\
\text { menolak } \\
\text { (package tidak } \\
\text { ada) }\end{array}$ & $\begin{array}{l}\text { Sistem } \\
\text { menolak }\end{array}$ & $\begin{array}{l}\text { Package tidak sesuai } \\
\text { dengan yang ada pada } \\
\text { sistem }\end{array}$ \\
\hline \multirow{4}{*}{$\begin{array}{l}\text { Activati } \\
\text { on } \\
\text { Date }\end{array}$} & $13 / 10 / 16$ & $\checkmark$ & $\begin{array}{l}\text { Date } \\
\text { check }\end{array}$ & $\begin{array}{l}\text { Sistem } \\
\text { menerima }\end{array}$ & $\begin{array}{l}\text { Sistem } \\
\text { menerima }\end{array}$ & \\
\hline & & $\checkmark$ & $\begin{array}{l}\text { Validity } \\
\text { check } \\
\text { Logical } \\
\text { relationshi } \\
p\end{array}$ & & & \\
\hline & $\begin{array}{ll}32 & \text { okt } \\
2016 & \end{array}$ & $\checkmark$ & $\begin{array}{l}\text { Reasonabl } \\
\text { eness } \\
\text { check }\end{array}$ & $\begin{array}{l}\text { Sistem } \\
\text { menolak } \\
(\text { tanggal 32) }\end{array}$ & $\begin{array}{l}\text { Sistem } \\
\text { menolak }\end{array}$ & $\begin{array}{l}\text { Tanggal yang } \\
\text { dimasukkan ke sistem } \\
\text { harus sesuai dengan } \\
\text { rentan waktu yang } \\
\text { sebenarnya }(1-31)\end{array}$ \\
\hline & $\begin{array}{l}13 / 10 / 16 \\
13 / 10 / 17\end{array}$ & $\begin{array}{l}\checkmark \\
\checkmark\end{array}$ & $\begin{array}{l}\text { Range } \\
\text { check } \\
\text { Limit } \\
\text { check }\end{array}$ & $\begin{array}{l}\text { Sistem } \\
\text { menolak } \\
\text { (tidak sesuai } \\
\text { format) }\end{array}$ & $\begin{array}{l}\text { Sistem } \\
\text { menolak }\end{array}$ & $\begin{array}{l}\text { Tanggal yang } \\
\text { dimasukkan tidak } \\
\text { sesuai dengan format } \\
\text { yang ada dalam sistem }\end{array}$ \\
\hline
\end{tabular}




\begin{tabular}{|c|c|c|c|c|c|c|}
\hline $\begin{array}{l}\text { Field } \\
\text { Name }\end{array}$ & $\begin{array}{c}\text { Dummy } \\
\text { Data }\end{array}$ & & $\begin{array}{c}\text { Tested } \\
\text { Control } \\
\text { (Option) }\end{array}$ & $\begin{array}{c}\text { Estimated } \\
\text { Result }\end{array}$ & $\begin{array}{c}\text { Occurred } \\
\text { Result }\end{array}$ & Conclusion/Finding \\
\hline \multirow[t]{2}{*}{ Amount } & $\begin{array}{l}\text { Rp. } \\
70.000,-\end{array}$ & $\checkmark$ & $\begin{array}{l}\text { Currency } \\
\text { check } \\
\text { Numeric } \\
\text { check }\end{array}$ & $\begin{array}{l}\text { Sistem } \\
\text { menerima }\end{array}$ & $\begin{array}{l}\text { Sistem } \\
\text { menerima }\end{array}$ & \\
\hline & $\begin{array}{l}\text { Tujuh } \\
\text { Puluh Ribu } \\
\text { Rupiah }\end{array}$ & $\checkmark$ & $\begin{array}{l}\text { Validity } \\
\text { check }\end{array}$ & $\begin{array}{l}\text { Sistem } \\
\text { menolak } \\
\text { (bukan } \\
\text { numerik) }\end{array}$ & $\begin{array}{l}\text { Sistem } \\
\text { menolak }\end{array}$ & $\begin{array}{l}\text { Harus sesuai dengan } \\
\text { format yang ditentukan } \\
\text { sistem }\end{array}$ \\
\hline
\end{tabular}

\subsection{Temuan dan Rekomendasi}

Selama melakukan audit, auditor mendapati beberapa temuan yang harus ditindak lanjuti. Untuk itu auditor memberikan rekomendasi mengenai temuan tersebut agar segera diperbaiki. Temuan serta rekomendasi tersebut dapat dilihat pada Tabel 7.

Tabel 7. Temuan dan rekomendasi

\begin{tabular}{l}
\hline \multicolumn{4}{c}{ Temuan } \\
\hline a. Setiap pelaporan error langsung \\
diinformasikan kepada pihak IT dan \\
penanganannya langsung secara regional \\
(Malaysia) serta dibuatkan dokumentasinya. \\
b. Terdapat seorang tenaga IT untuk \\
menanggunlangi trouble, namun secara \\
garis besar setiap trouble secara keseluruhan \\
diawasi langsung oleh divisi IT yang \\
terdapat pada regional (Malaysia).
\end{tabular}

Uninterruptible power supply (UPS) belum terpasang pada setiap PC.

Sistem maintenance terjadi 2 kali dalam setahun, maintenance dilakukan agar semua hal yang menunjang sistem dapat berjalan dengan baik dan semua proses didokumentasikan.

Setiap hak akses diberikan berdasarkan otorisasi langsung dari atasan melalui sistem. Untuk proses penghapusan user id serta email ketika karyawan keluar (resign) akan dievaluasi dan secara langsung terjadi pada sistem.

Proses pengecekan apabila terjadi perubahan aplikasi :

a. Semua perubahan harus mendapatkan otorisasi langsung dari atasan, semua file serta program di awasi oleh atasan.

b. Divisi IT yang berada di Malaysia (regional) yang mendapatkan akses penuh untuk melakukan perubahan pada sistem.

c. Setiap perubahan yang terjadi dicatat dan dibuatkan dokumentasi sebagai pelaporan

Sebaiknya pada tiap departemen ditambah tenaga IT jangan hanya satu orang, karena apabila sewaktu-waktu terjadi trouble pada jaringan tiap departemen maka tenaga IT tersebut tidak terlalu repot dalam melakukan perbaikan serta semakin cepat dalam penanggulangannya. Mengingat aplikasi JBOS ini menggunakan jaringan yang rentang juga terdahap trouble.

Mengingat bahwa semua operasional perusahaan saat ini sudah computerized, maka sangat penting untuk memiliki UPS yang terpasang pada setiap PC karena apabila sewaktu-waktu terjadi pemadaman listrik UPS tersebut berfungsi untuk membantu PC tetap menyala dan dapat menyimpan semua pekerjaan yang sedang dikerjakan sambil menunggu aktifnya pembangkit listrik emergency.

Sebaiknya sistem maintenance dilakukan dalam 3 bulan mengingat banyaknya aktivitas yang terjadi di dalam sistem tersebut dan juga maintenance yang dilakukan lebih baik terurut sesuai dengan kebutuhan.

Dalam hal pemberian hak akses, penghapusan user id dan email sebaiknya dilakukan evaluasi dan pelaksanaannya dalam waktu kurang dari 24 jam, agar semua user yang akan terekam di sistem dan yang akan dihapus oleh sistem dapat di akses dengan cepat.

Dalam hal perubahan sistem atau aplikasi sebaiknya dilakukan dengan cepat dan disosialisasikan dengan cepat, mengingat banyaknya user yang terhubung dalam aplikasi ini dan juga divisi IT harus bergerak cepat dalam hal melakukan perubahan sistem serta maintenance. Paling tidak apabila terjadi perubahan pada sistem, sistem sudah dipasang notification agar tiap user yang terhubung dengan sistem dapat mengetahui hal tersebut. 


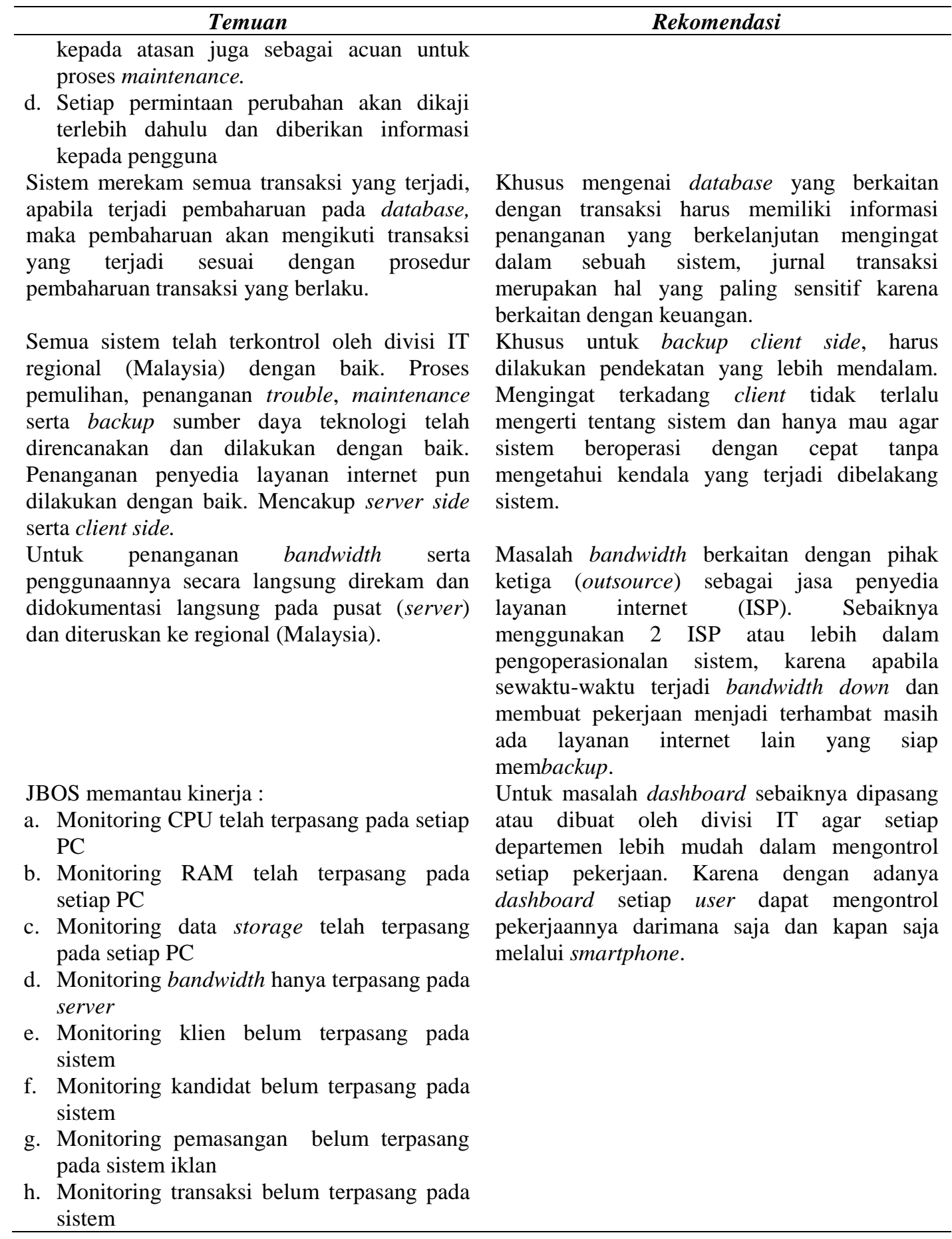

\section{KESIMPULAN}

Pengendalian (Environmental Controls dan Logical Controls) pada PT. XYZ telah sesuai dengan ketentuan atau prosedur yang ada, baik dalam hal keamanan gedung kantor sampai kepada aplikasi yang digunakan. Namun yang perlu diperhatikan adalah pada physical controls dan IS controls karena terdapat beberapa temuan yang belum sesuai dengan ketentuan atau prosedur.

Berdasarkan temuan yang paling besar resikonya adalah Uninterruptible power supply (UPS) yang belum terpasang pada setiap PC, karena apabila sewaktu-waktu terjadi pemadaman listrik UPS tersebut berfungsi untuk membantu PC tetap menyala dan dapat menyimpan semua pekerjaan yang sedang dikerjakan sambil menunggu aktifnya pembangkit listrik emergency.

Masalah bandwidth berkaitan dengan pihak ketiga (outsource) sebagai jasa penyedia layanan internet (ISP). Sebaiknya menggunakan 2 ISP atau lebih dalam pengoperasionalan sistem, karena apabila 
sewaktu-waktu terjadi down bandwidth dan membuat pekerjaan menjadi terhambat masih ada layanan internet lain yang siap membackup.

Monitoring klien, monitoring kandidat, monitoring pemasangan iklan, monitoring transaksi adalah hal penting, untuk itu sebaiknya dipasang atau dibuat dashboard oleh divisi IT agar setiap departemen lebih mudah dalam mengontrol setiap pekerjaan. Karena dengan adanya dashboard setiap user dapat mengontrol pekerjaannya darimana saja dan kapan saja melalui smartphone.

\section{DAFTAR PUSTAKA}

[1] Arza FI. Proses Audit pada Era Teknologi Informasi serta Implikasi terhadap Pembelajaran Auditing di Perguruan Tinggi. Akunt Manaj. 2007;2(2):23-31.

[2] Chen Y, Zhang H, Tang Z. The Interaction of The Sound and Color Stimuli in The Auditory and Visual Cortexes. Int J Comput Sci Netw Secur [Internet]. 2011;11(7):81-3. Available from: http://paper.ijcsns.org/07_book/201107/20110713.pdf

[3] Chimmanee S, Veeraprasit T, Srisa-an C. A Performance Evaluation of Vulnerability Detection: NetClarity Audito, Nessus , and Retina. Int J Comput Sci Netw Secur. 2014;14(3):34-41.

[4] Maria E, Haryani E. Audit Model Development of Academic Information System : Case Study on Academic Information System of Satya Wacana. J Art, Sci Commer. 2011;II(April 2011):12-24.

[5] Nugroho M. Audit Lingkungan TI: Perspektif Dan Dampak Pada Proses Auditing Secara Komprehensif. Pendidik Akunt Indones. 2011;IX(1):24-42.

[6] Omosh HAM, Bani-Ahmad A, Kh. E-DAE-R. The Effect of Applying the Information Technology Audit Standard\# 21 on the Risk Related To ERP System in the Jordanian Companies. Glob J Manag Bus Res [Internet]. 2014;14(1):1-9. Available from: http://www.journalofbusiness.org/index.php/GJMBR/article/view/1212

[7] Raggad BG, Collar EJ. The Simple Information Security Audit Process : SISAP. Int J Comput Sci Netw Secur Comput Sci Sci. 2006;6(6):189-98.

[8] Setiawan H, Mustofa K. Metode Audit Tata Kelola Teknologi Informasi di Instansi Pemerintah Indonesia. IPTEK-KOM. 2013;15(1):1-15.

[9] Utomo AP. Dampak Pemanfaatan Teknologi Informasi terhadap Proses Auditing dan Pengendalian Internal. J Teknol Inf Din. 2006;XI(2):66-74.

[10] Yulianti DT, Patria MC. Audit Sistem Informasi Sumber Daya Manusia Pada PT X Menggunakan Cobit Framework 4.1. Sist Inf. 2011;6(1):15-33. 